\title{
A PESQUISA DO TIPO ETNOGRÁFICA: uma proposta de abordagem metodológica de pesquisa em Educação Matemática
}

\author{
Raimundo Sant os de Castrol
}

\section{RESUMO}

O presente artigo é derivado das reflexões metodológicas de pesquisa de doutorado, desenvolvida na Universidade Federal de São Carlos - UFSCar, intitulada "Jogos de Linguagem Matemáticos da Comunidade Remanescente de Quilombos da Agrovila de Espera, Município de Alcântara, Maranhão". Tem por objetivo discutir uma proposta metodológica para pesquisas em Educação Matemática: a pesquisa do tipo etnográfica. Esta modalidade de pesquisa foi aplicada no estudo supracitado, que visava descrever e caracterizar as práticas matemáticas, compreendidas como jogos de linguagens matemáticos, dos indivíduos membros da comunidade. Após as análises realizadas no estudo em questão, compreendese que as pesquisas do tipo etnográficas podem contribuir para a reflexão, sobre um conjunto de elementos socioculturais, dentre eles, as práticas matemáticas, favorecendo as descrições, comparações e interpretações sobre os sentidos e significados atribuídos a tais práticas pelos membros da comunidade. Desta forma, as pesquisas em Educação Matemática, sobretudo, aquelas que buscam adentrar numa particularidade sem, no entanto, que isso se confunda com uma suposta "universalidade", pela natureza investigativa desse tipo de pesquisa e pelo cenário no qual se desenvolve, pode por meio das pesquisas do tipo etnográficas, proporcionar uma reflexão sistemática sobre o fenômeno em estudo e sobre quem é o pesquisador na própria pesquisa. É preciso dizer, ainda, que esse tipo de pesquisa não busca promover intervenções, mas, sim, conhecer e compreender os arranjos e os rearranjos cotidianos da comunidade em estudo, discutindo a sua realidade e favorecendo a compreensão de parte dos significados e sentidos produzidos em seu interior, em especial naquilo que se refere às suas práticas sociais que, de alguma maneira, env olvem aspectos relativ os à Educação Matemática.

Palavras-chave: Pesquisas. Ełnografia. Educação Matemática.

\section{RESEARCH OF THE ETHNOGRAPHIC TYPE: a proposal of a methodological}

$$
\text { approach of research in Mathematical Education }
$$

\begin{abstract}
This article is derived from the methodological reflections of doctoral research developed at the Federal University of São Carlos - UFSCar, entitled Mathematical

1 Doutor em Educação pela Universidade Federal de São Carlos - SP; Mestre em Educação pela Universidade Federal do Maranhão (2009); Professor do Departamento de Matemática do Instituto Federal de Educação, Ciência e Tecnologia do Maranhão - IFMA, Campus São Luís - Monte Castelo. ORCID iD: https://orcid.org/0000-0001-6762-836X. E-mail: raicastro@ifma.edu.br
\end{abstract}


Language Mathematics of the Remaining Community of Quilombos of Agrovila de Espera, Municipality of Alcântara, Maranhão. It aims to discuss a methodological proposal for research in Mathematics Education: ethnographic research. This type of research design was adopted in the study discussed in this paper, which aimed to describe and characterize the mathematical practices, understood as games of mathematical languages, of individuals members of the community. The results of the analyzes carried out in the study in question, indicate that ethnographic research can contribute to the reflection on a set of sociocultural elements, among them mathematical practices, fav oring the descriptions, comparisons and interpretations of meanings attributed to such practices by members of the community. In this way, studies in Mathematics Education, especially those that seek to enter a particularity, without, however, being confused w ith a supposed "universality", by the inv estigative nature of this type of research and by the scenario in which it is developed, can by through ethnographic research, provide a systematic reflection on the phenomenon under study and on who is the researcher in the research itself. It should also be said that this type of research does not seek to promote interventions, but rather to know and understand the daily arrangements and rearrangements of the study community, discussing their reality and favoring the understanding of some of the meanings and meanings produced in its interior, in particular, in what refers to its social practices that, in some way, involve aspects related to Mathematics Education.

Keywords: Research. Ethnography. Mathematical Education.

\section{LA INVESTIGACIÓN DEL TIPO ETNOGRÁFICO: una propuesta de enfoque metodológico de investigación en Educación Matemática}

\section{RESUMEN}

El presente artículo se deriv a de las reflexiones metodológicas de investigación de doctorado desarrollada en la Universidad Federal de São Carlos - UFSCar, titulada "Juegos de Lenguaje Matemáticos de la Comunidad Remanente de Quilombos de la Agrovila de Espera, Municipio de Alcántara, Maranhão". Tiene por objetiv o discutir una propuesta metodológica para investigaciones en Educación Matemática: la inv estigación del tipo etnográfico. La misma fue aplicada en el estudio citado que pretendía describir y caracterizar las prácticas matemáticas, comprendidas como juegos de lenguajes matemáticos, de los individuos miembros de la comunidad. Después de los análisis realizados en el estudio en cuestión, se comprende que las investigaciones del tipo etnográfico pueden contribuir a la reflexión sobre un conjunto de elementos socioculturales, entre ellos las prácticas matemáticas, fav oreciendo las descripciones, comparaciones e interpretaciones sobre los sentidos y significados atribuidos a tales prácticas por los miembros de la comunidad. De esta forma, las investigaciones en Educación matemática, sobre todo aquellas que buscan adentrarse en una particularidad sin, sin embargo, que esto se confunda con una supuesta "universalidad", por la naturaleza investigativa de este tipo de investigación y por el escenario en que se desarrolla, puede por medio de las inv estigaciones del tipo etnográfico, proporcionar una reflexión sistemática sobre el fenómeno en estudio y sobre quién es el inv estigador en la propia investigación. Es necesario decir, aún, que ese tipo de investigación no busca promover intervenciones, sino, sí, conocer y comprender los arreglos y los reordenamientos

Revista Exitus, Santarém/PA, Vol. 9, №3, p. 252 - 279, JUL/SET 2019. 
cotidianos de la comunidad en estudio, discutiendo su realidad y fav oreciendo la comprensión de parte de los significados y sentidos producidos en su interior, sobre todo, en lo que se refiere a sus prácticas sociales que, de alguna manera, inv olucra aspectos relativos a la Educación Matemática.

Palabras clave: Investigaciones. Etnografía. Educación Matemática.

\section{INTRODUÇÃO}

Este texto é fruto das reflexões metodológicas de pesquisa de doutorado, desenvolvida na Universidade Federal de São Carlos - UFSCar, intitulada "Jogos de Linguagem Matemáticos da Comunidade Remanescente de Quilombos da Agrovila de Espera, Município de Alcânt ara, Maranhão". Teve por objetivo compreender o que está manifesto nas práticas matemáticas, dos membros da comunidade em suas práticas sociais cotidianas, problematizando-as, a partir de sua não universalização e decodificando os efeitos de significados e sentidos atribuídos a elas pelos membros da comunidade.

O estudo originário foi desenvolvido por meio de uma pesquisa qualitativa do tipo etnográfica. Suas discussões e análises foram auxiliadas pela microanálise etnográfica ${ }^{2}$, com o apoio dos elementos filosóficos do pensamento de Ludwig Wittgenstein, sobretudo, a noção de jogos de linguagem. O mesmo refletiu acerca das implicações sofridas pela comunidade remanescente de quilombos da cidade de Alcântara, Maranhão, mais especificamente a da Agrovila de Espera, a partir das desapropriações, deslocamentos, reassentamentos e, consequentemente, da compulsória aproximação da zona urbana, em decorrência de toda a problemática criada pela implantação do Centro de Lançamentos de Alcântara-CLA.

De acordo com Castro e Caldeira (2017), as discussões acerca da situação das comunidades remanescentes de quilombos no Brasil não são recentes. Os autores apontam que, nos estudos realizados, depararam-se com uma série de pesquisas que discutiam os mais variados temas

\footnotetext{
2 Será discutido com maior profundidade à frente.
} 
relacionados a este assunto e, em Educação Matemática, parte significativa delas discutia a Ełnomatemática destes grupos sociais.

Ainda para Castro e Caldeira (2017), especificamente no Maranhão, grande parte das pesquisas encontradas, consistia em estudos sociológicos, históricos e um elevado número de estudos antropológicos. Estes últimos, em linhas gerais, em Alcântara - MA, visavam discutir a constituição de comunidades como remanescentes de quilombos e a problemática criada pela implantação do CLA. Os estudos apontados discutiam temas relativos à vida sociocultural destes povos, a forma pormenorizada com que se constituíam em comunidades como territórios quilombolas e os problemas enfrentados pelas pessoas desde os anos de 1980 do século passado, em função da implantação do CLA.

Também para Castro e Caldeira (2017), o Laudo Antropológico "Os Quilombolas e a Base de Lançamento de Foguetes de Alcântara (ALMEIDA, 2006)", por exemplo, relata a busca pelo reconhecimento do direito à terra e, consequentemente, o direito à garantia de existência destes povos como remanescentes de quilombos, como estes têm sofrido constantes ameaças e a perda sistemática dos seus elementos socioculturais.

É importante destacar que não consiste em objetivo deste texto tratar do tema das problemáticas sofridas pela comunidade em decorrência da implantação da Base. A menção feita acima é apenas para situar o leitor acerca das problemáticas sociais decorrentes das desapropriações, deslocamentos e reassentamentos compulsórios das comunidades remanescentes de quilombos de Alcântara-MA.

Como dito linhas acima, o objeto de discussão deste texto, que corresponde à parte dos estudos realizados para o desenvolvimento da pesquisa originária, e, consequentemente, o seu eixo central, é a pesquisa do tipo etnográfica como alternativa metodológica para pesquisas em Educação Matemática. Desta forma, a compreendemos como possibilidade metodológica, viável e bastante plausível para a descrição das práticas matemáticas, caracterizadas como jogos de linguagem matemáticos, dos sujeitos da pesquisa. Neste sentido, consideramos que o ver e o ouvir foram 
ações importantes. Isto posto, compreendemos que a tarefa proposta na pesquisa só seria efetivamente possível se a investigação partisse do seio da própria comunidade.

Para o desenvolvimento da investigação, ou seja, para o seu movimento metodológico interno, partiu-se do campo, de dentro da comunidade, para dele tentar encontrar sentido na e da investigação. À vista disso, foi preciso compartilhar de seus espaços, dos seus ritos religiosos, de suas tarefas diárias, de suas vidas. Isto, em nossa compreensão, forneceu elementos que possibilitaram as descrições - elemento do desenvolvimento de uma pesquisa do tipo etnográfica - que favoreceram as compreensões, as problematizações e as análises que foram elaboradas.

\title{
1 A COMPREENSÃO DE CIÊNCIA, PESQUISA E METODOLOGIA DE PESQUISA
}

Para podermos buscar compreender o que queremos propor, de início, temos aspectos importantes acerca de ciência, pesquisa e metodologia de pesquisa que consideramos relevantes e dos quais concordamos. Desta forma, de acordo com Freitas e Prodanov (2013, p. 11), "para cada ciência, os recursos utilizados são determinados por sua própria natureza". Sendo assim, precisamos entender que o percurso metodológico adotado por uma pesquisa tem que levar em consideração seus aspectos filosóficos, além, é claro, de suas outras características internas.

\begin{abstract}
A Metodologia é compreendida como uma disciplina que consiste em estudar, compreender e avaliar os vários métodos disponíveis para a realização de uma pesquisa acadêmica. A Metodologia, em um nível aplicado, examina, descreve e avalia métodos e técnicas de pesquisa que possibilitam a coleta e o processamento de informações, visando ao encaminhamento e à resolução de problemas e/ou questões de investigação (FREITAS; PRODANOV, 2013, p. 14).
\end{abstract}

Ainda, de acordo com Freitas e Prodanov (2013, p. 14), em se tratando de pesquisas científicas e seus métodos, para que possamos efetivamente compreender suas características, precisamos previamente compreender 0 que vem a ser Ciência. Neste sentido, os autores discutem seu significado a partir da própria etimologia da palavra, qual seja, "O termo ciência provém 
do verbo em latim Scire, que significa aprender, conhecer". Discutem ainda os "critérios de cientificidade", dos quais destacamos aqueles que, em nossa compreensão, auxiliam-nos na busca por entendermos os sentidos e significados das pesquisas que realizamos:

objeto de estudo bem-definido e de natureza empírica: delimitação e descrição objetiva e eficiente da realidade empiricamente observável, isto é, daquilo que pretendemos estudar, analisar, interpretar ou verificar por meio de métodos empíricos;

discutibilidade: significa a propriedade da coerência no questionamento (...). Trata-se de conjugar crítica e autocrítica, dentro do princípio metodológico de que a coerência da crítica está na autocrítica. Conhecimento científico é o que busca se fundamentar de todos os modos possíveis e imagináveis, mas mantém consciência crítica de que alcança esse objetivo apenas parcialmente, não por defeito, mas por tessitura própria do discurso científico;

originalidade: refere-se à expectativa de que todo discurso científico corresponda a alguma inovação, pelo menos, no sentido reconstrutivo;

coerência: argumentação lógica, bem-estruturada, sem contradições;

sistematicidade: parceira da coerência, significa o esforço de dar conta do tema amplamente, sem exigir que se esgote, porque nenhum tema é, propriamente, esgotável (...);

consistência: base sólida, refere-se à capacidade do texto de resistir à contra-argumentação ou, pelo menos, merecer o respeito de opiniões contrárias; em certa medida, fazer ciência é saber argumentar, não só como técnica de domínio lógico, mas sobretudo como arte reconstrutiva;

linguagem precisa: sentido exato das palavras, restringindo ao máximo o uso de adjetivos;

relevância social: os trabalhos acadêmicos, em qualquer nível, poderiam ser mais pertinentes, se também fossem relevantes em termos sociais, ou seja, estudassem temas de interesse comum, se se dedicassem a confrontar-se com problemas sociais preocupantes;

ética: procura responder à pergunta: a quem serve a ciência? (...). A visão ética dedica-se sobremaneira a direcionar tamanha potencialidade para o bem-comum da sociedade, no sentido mais preciso, em primeira instância, evitar que os meios se tornem fim; segundo, que se discutam não só os meios, mas também os fins e, terceiro, assegurar que os fins não justifiquem os meios;

intersubjetividade: opinião dominante da comunidade científica de determinada época e lugar (FREITAS; PRODANOV, 2013, p. 17-20).

Assim, ainda de acordo com estes autores, tendo por base os critérios de cientificidades apontados, para que seja "considerado científico", o conhecimento produzido deve ter as particularidades de seu objeto ou fenômeno de estudo analisadas de maneira fundamentada e metodologicamente bem definidas. 
Destaque dado ao fato de que, para os autores, ao analisarmos um fato, o conhecimento científico sobre este, busca-se não apenas explicá-lo, mas, também, descobrir, redescobrir, encontrar, reencontrar, desistir, insistir, começar, recomeçar e, portanto, fazer relações com outros fatos, permitindo, deste modo, conhecer a realidade e ampliar o conhecimento. Portanto, o método adotado para o desenvolvimento da pesquisa deve ser compreendido como o caminho, uma via de acesso, mas não uma estrada rígida e concretada na "certeza de nossa sabedoria".

Podemos definir método como caminho para chegarmos a determinado fim. E método científico como o conjunto de procedimentos intelectuais e técnicos adotados para atingirmos 0 conhecimento(...). Método científico é o conjunto de processos ou operações mentais que devemos empregar na investigação. É a linha de raciocínio adotada no processo de pesquisa (FREITAS; PRODANOV, 2013, p. 24).

Podemos destacar que o conhecimento científico tem por eixo o emprego de formas de métodos, técnicas e análises do objeto ou do fenômeno de estudo, de maneira que seja possível cumprir com alguns critérios estabelecidos para discutir e produzir novas maneiras de apreender a realidade e novos conhecimentos, mas isso não pode se dar de maneira rígida e, sim, sempre que for necessário pode ser repensado, refeito.

\section{A PESQUISA DO TIPO ETNOGRÁFICA}

A etnografia, de acordo com Chizzotti (2013), significa a descrição de um grupo social. Etimologicamente, deriva da palavra grega graphein (descrever) e ethnos (estrangeiro, bárbaro). Posteriormente, o termo foi utilizado para descrever um grupo cultural específico, introduzido pela antropologia como a forma de descrição social científica de uma pessoa ou da configuração, de uma cultura ou de uma população.

As pesquisas do tipo etnográficas fazem uso de aspectos da etnografia, mas não se trata da etnografia no sentido das realizadas pelos antropólogos. Constituem-se e fundamentam-se a partir de elementos da pesquisa etnográfica, sobretudo, das técnicas que emprega. Mas 
distinguem-se, no que diz respeito ao tempo, da forma com que ocorre a inserção no meio e a atitude do pesquisador quanto a isso.

É importante destacar que isso nada tem a ver com um certo "descaracteriza" os aspectos da etnografia, para que seja considerada "uma pesquisa do tipo etnográfica". Como veremos mais à frente, (1) embora o tempo de inserção seja diferente entre elas, ele tem que ser o necessário para que haja minimamente a apreensão daquilo que os objetivos da pesquisa buscam captar; (2) a forma de inserção considera os aspectos do local, do ambiente e as pessoas envolvidas de maneira que o pesquisador faça parte da pesquisa, mas que tenha consciência que não se está trabalhando na perspectiva da prática antropológica.

Destaque dado aqui neste momento ao auxílio da microanálise etnográfica para a discussão dos dados da pesquisa originária. Isto posto, de acordo com Mattos (2011), a microanálise etnográfica é um instrumento da etnografia utilizado com frequência em estudos da sociolinguística da comunicação, microanálise sociolinguística, dentre outros, que à medida que dá ênfase ao significado das formas de envolvimento das pessoas como atores do processo, também exige que o investigador detalhe de maneira criteriosa os comportamentos observados por meio da "(...) transcrição linguística verbal e não-verbal, olhares, pausas, tom de voz, detalhes da interação e o que isso significa" (MATTOS, 2011, p. 55-56).

\footnotetext{
A microanálise etnográfica leva em consideração não somente a comunicação ou interação imediata da cena, como também a relação entre esta interação e o contexto social maior, a sociedade onde este contexto se insere (MATOS, 2011, p. 56).
}

De acordo com Mattos e Castro (2011), a microanálise etnográfica é considerada micro porque estuda um evento ou parte dele, dando ênfase ao estudo das relações sociais do grupo como o todo. Ou seja, procurar identificar nas relações sociais o significado do grupo para um evento, um fenômeno que se manifesta no interior deste grupo, cabendo ao final das descrições e de todo o processo que as envolve, a constituição de 
conhecimento oriundo deste mesmo grupo, seja este significado de classe, etnia, linguagem, gênero, etc.

A microanálise etnográfica centra-se na interação do pesquisador com os sujeitos e com o ambiente no qual se desenvolve, destacando-se os padrões ou não, os descompassos, as formas de entendimentos - tanto do pesquisador, quanto dos sujeitos - acerca do que é pesquisado. Desta maneira, as descrições oriundas deste processo, obtidas com auxílio das técnicas de coleta de dados empregadas, favorecem as compreensões sobre as práticas sociais do grupo e, mais ainda, no caso em tela, possibilitam analisar as práticas matemáticas dos sujeitos da pesquisa, que deram origem a esse texto, envolvidos em suas atividades cotidianas.

Ainda para Mattos (2011, p. 56), "a etnografia, em geral, serve de background para a microetnografia". Desta feita, em consonância com Chizzotti (2013), a pesquisa etnográfica caracteriza-se pela descrição ou reconstrução de mundos culturais, fazendo um registro detalhado, descrevendo práticas, artefatos e revelando comportamentos, interpretando significados e as interações sociais que deles derivam. Quanto ao pesquisador, este deve permanecer durante certo período inserido no campo de estudo, buscando na vida cotidiana os elementos geograficamente determinados e partilhando de suas práticas, hábitos, rituais, concepções, buscando compreendê-los, livre de quaisquer preconceitos.

Da mesma maneira, de acordo com Lima et al. (1996, p. 24), "nesta modalidade de investigação, a observação, a descrição e a análise das tradições da população que está sendo estudada, são passos essenciais para sua compreensão". Ou seja, o investigador, imbuído da necessidade de estar presente, é o "olho" da pesquisa e, como tal, faz do seu convívio com a população e de seus filtros pessoais, elementos que subsidiarão a busca por significados sem, no entanto, deixar de considerar o olhar do outro.

Novamente, Mattos (2011) nos auxilia a compreender que a pesquisa etnográfica é, explícita ou implicitamente, em sua maior parte, guiada pelas 
questões propost as pelo investigador. Isso não quer dizer que se traduza num processo de mão única, pelo contrário. O ambiente no qual se desenvolve, possibilita alternância ou mesmo mudança no que foi previamente planejado, uma vez que, aquilo que se busca compreender é parte de ações humanas e, por conta disso, também passíveis de serem modificadas.

Como consequência, as técnicas que emprega, via de regra, devido aos imperativos e demandas da própria pesquisa, no que se refere aos seus aspectos internos e externos, são muitas e muitas vezes revistas e constantemente refeitas. Isso faz com que as compreensões que busca alcançar sejam alvo de uma dinâmica diferente e de constantes interrogações. Cabe, portanto, ao investigador, compreender que a prática da pesquisa etnográfica requer momentos de reflexão sobre a sua ação e, por conseguinte, sobre o desenvolvimento da pesquisa.

As pesquisas do tipo etnográfica acompanham esta linha de ação e reflexão e, da mesma maneira, podem ser constantemente refeitas e terem seus objetivos, bem como as técnicas que empregam, alteradas com o caminhar sem que isso cause prejuízos às análises empreendidas. Esta reflexão está calcada, dentre outras coisas, nos cuidados que se deve ter ao realizar os trabalhos de campo.

Cuidados estes que passam, inclusive, pelas características da pesquisa e de respeitos éticos, tanto no que se refere às populações em estudo quanto aos critérios que tornam a abordagem adotada compreensível e possível de ser realizada. Destarte, é importante compreender a etnografia como parte de um estudo das relações mais amplas que se estabelecem no seio de uma população, bem como ter em mente que, apesar de frutífera em termos científicos, cabe ao investigador evitar enveredar-se por caminhos que a tornem meramente uma descrição sem sentido, sem nenhum vínculo com o tema em estudo, sendo este um cuidado fundamental para as compreensões as quais a pesquisa propõe.

Além dos cuidados descritos acima, quando aplicados às pesquisas que envolvem grupos sociais em estado de alguma fragilidade, há ainda os que devem ser tomados no que diz respeito às características culturais da 
população em estudo, pois, como evidenciam Sousa e Barroso (2008, p. 153), "os trabalhos etnográficos devem enxergar os informantes como pessoas que, por possuírem algumas características culturais diferentes, merecem uma investigação", ou, mais ainda, com base nisso, os estudos etnográficos devem, além de considerar "(...) o perfil do investigador, as características do campo e a abordagem ética".

Por outro lado, por se tratar de uma abordagem que, necessariamente, tem na presença de quem investiga, como um dos elementos que a constituem, é igualmente importante que suas palavras ao longo das descrições estejam de acordo com seus filtros e que tragam no seu bojo as características pessoais de quem a faz. Isso, no entanto, deve ser realizado sem que se levante julgamentos e juízo de valor, que podem descaracterizá-la enquanto proposta de pesquisa. Desta forma, Lima et al. (1996, p. 24) destacam que, para a utilização deste tipo de abordagem:

O julgamento, avaliação e ou configuração das condutas observadas não fazem parte desta metodologia. Consequentemente, o êxito deste tipo de investigação depende em grande parte da sensibilidade do pesquisador diante das situações com as quais se depara e da interação que estabelece com a população em estudo.

De acordo com Sousa e Barroso (2008), na pesquisa etnográfica é importante que o observado e as interações resultantes da observação sejam apresentados aos leitores com o devido cuidado, para que o sentido do trabalho da pesquisa etnográfica não seja perdido e não se restrinja apenas ao desenvolvimento do investigador, mas, também, seja uma maneira eficaz de informar acerca da condição humana, com vistas a colaborar no seu desenvolvimento.

Com base nas informações acerca das pesquisas etnográficas e as relações que tentamos estabelecer acima com as pesquisas do tipo etnográficas, podemos destacar que esta, adotada para o desenvolvimento da pesquisa que originou este texto, tem a característica de obter uma descrição referenciada acerca dos fatos observados, por meio de uma 
interpretação própria do investigador. Nesse sentido, a sensibilidade de quem investiga é fator preponderante nas ações tomadas no trabalho de campo.

As observações realizadas e que serviram de base para as descrições na pesquisa, levaram em conta este aspecto, e tiveram muito a ver com o que é visto, percebido, comparado, analisado, para que as relações desenvolvidas tivessem coerência. Isso só foi possível porque se acredita que, imbuído do trabalho investigativo, o investigador foi sensivel à sensibilidade do outro, do observado. Ou seja, o investigador teve a sensibilidade necessária para perceber no outro, no investigado, aquilo que o toca enquanto ser humano.

Buscar os significados das relações que se estabelecem entre quem investiga e quem é investigado é o que dá suporte ao desenvolvimento da pesquisa do tipo etnográfica. Atentar para esta particularidade é essencial para que a pesquisa alcance seus objetivos. Além disso, as falas, os gestos e os modos com que os membros da população investigada se interrelacionam e se constituem em sociedade, os padrões, similaridades e diferenças, devem ser ressaltados, pois auxiliam na descrição e na busca de compreensões acerca dos fatos estudados, sejam eles quais forem.

De acordo com Magnani (2009), ao propor uma discussão a partir de alguns usos da etnografia fora do campo da antropologia, com base em alguns autores que fizeram uso desta abordagem de pesquisa e até de muitos antropólogos, a etnografia é uma forma especial de operar, em que o pesquisador, em contato com o universo dos pesquisados, compartilha de seu horizonte sem, no entanto, permanecer e menos ainda, como forma de confirmar a lógica de sua visão de mundo. Diz ainda que isso deve acontecer em uma relação de troca, ao comparar suas teorias com as deles e, assim, constituir um novo modelo de entendimento.

Este autor faz ainda algumas considerações que julga importantes para o entendimento e utilização da etnografia como abordagem de pesquisa. Dentre elas, destaco a que, segundo ele, primeiramente deve-se distinguir entre "prática etnográfica" de "experiência etnográfica", sendo 
que a prática se refere a uma atividade programada e contínua, e a experiência é descontínua e imprevista. Depois, ainda de acordo com Magnani (2009, p. 136), é necessário compreender que:

\begin{abstract}
A etnografia é o método próprio do trabalho da antropologia em sentido amplo, engloba as estratégias de contato e inserção no campo, condições tanto para a prática continuada como para a experiência etnográfica e que levam à escrita. Condição para seu exercício pleno é a vinculação a escolhas teóricas, o que implica não poder ser destacada como conjunto de técnicas (observação participante, aplicação de entrevistas, etc.) empregadas, independentemente de uma discussão conceitual.
\end{abstract}

Para este autor, existe o pressuposto da totalidade, que é algo presente nas pesquisas antropológicas desde as etnografias clássicas. Assim, não se trata daquela totalidade do todo orgânico, sem funcionalidade e conflitos, mas, no tocante à etnografia, conforme Magnani (2009, p. 137), diz respeito à "(...) forma como é vivida pelos atores sociais de um lado e, de outro, como é percebida e descrita pelo investigador".

Em síntese, Magnani (2009, p. 138) sustenta que:

\begin{abstract}
Uma totalidade consistente em termo da etnografia é aquela que, experimentada e reconhecida pelos atores sociais, é identificada pelo investigador, podendo ser descrita em termos categoriais: se para aqueles constitui o contexto da experiência diária, para o segundo pode também se transformar em chave e condição de inteligibilidade. Posto que não se pode contar com uma totalidade dada, postula-se uma, nunca fixa, a ser construída a partir da experiência dos atores e com a ajuda de hipóteses de trabalho e escolhas teóricas, como condição para que se possa dizer algo mais do que generalidades e platitudes a respeito do objeto de estudo.
\end{abstract}

As pesquisas do tipo etnográficas estão longe de caracterizar-se como um estudo antropológico nos termos apontados por Magnani (2009), mas, de alguma forma, aproximam-se mais de uma "experiência etnográfica". É importante destacar que o autor se refere às pesquisas etnográficas de cunho urbano, que têm seu foco voltado para cidades e atores sociais a elas pertencentes.

Aqui, foi mencionada como forma de diferenciá-la ou mesmo de contrapô-la à sua maneira de utilização da etnografia como abordagem de

Revista Exitus, Santarém/PA, Vol. 9, №3, p. 252 - 279, JUL/SET 2019. 
pesquisa em diferentes ambientes que, no caso específico da proposta original apresentada no estudo realizado, diz respeito à constituição sociocultural, política e circunscrita a uma comunidade tradicional que preserva características próprias e distintas de comunidades presentes em zonas urbanas.

No entanto, em termos teóricos e conceituais, muitas das discussões propostas por Magnani (2009) podem servir para auxiliar nas reflexões elaboradas. Escrevemos isto uma vez que, guardados os devidos cuidados para não cometer grandes equívocos, as dinâmicas empreendidas, o foco não particularista, os trajetos epistemológicos que favorecem a ampliação teórica sobre o tema e o olhar que garante e permite captar as sutilezas e proximidades inerentes a toda pesquisa etnográfica são elementos importantes que o autor utilizou em suas análises e que foram bastante úteis.

Ora, considerando as experiências pessoal e coletiva implicadas no ato de realizar pesquisas etnográficas, não é possivel deixar de lado os elementos apontados no parágrafo acima, mesmo que tais elementos não digam respeito às etnografias realizadas em comunidades remanescentes de quilombos - em geral realizadas por pesquisas antropológicas - que têm suas particularidades, mas que são grupos humanos socialmente determinados, como aqueles que constituem comunidades urbanas.

No desenvolvimento de pesquisas do tipo etnográficas que possuem seu foco voltado para tais grupos sociais culturalmente estabelecidos, a preocupação do investigador deve se ater a tentar não fugir em demasia dos pressupostos da pesquisa. É com base nisso que consideramos que Magnani (2009) traz uma contribuição significativa para a nossa própria compreensão acerca do que é realizar esse tipo de pesquisa.

Com isso, o estudo desenvolvido, e que deu base para este texto, utilizou diversificadas estratégias, técnicas e meios com o auxílio dos mais variados instrumentos de registros, de modo que podemos citar:

(1) as técnicas de observação com registro em áudio, vídeo, no diário de campo e de entrevistas semiestruturadas individuais e em grupos, foram 
fundamentais para que os registros fossem feitos de maneira que se pudesse ser o mais verdadeiro possível quando de suas análises;

(2) o tempo foi o tempo possível, mas foi também aquele que teve na sensibilidade do pesquisador o "alarme" necessário para saber quando, onde e porque era possível "intervir" e, mais ainda, de que maneira essa "intervenção" poderia ser feita. Desta forma, buscou-se permanecer na comunidade o tempo necessário para que, minimamente, os meios adotados pudessem possibilitar a compreensão do seu cotidiano, de suas tarefas diárias, de suas relações sociais e de suas relações com o trabalho e a natureza;

(3) com descrição referenciada, a partir das observações e registros feitos, buscou-se dar subsídios para as problematizações e análises por meio da lente teórica adotada e foi conduzida de maneira a produzir resultados de forma narrativa.

A tarefa proposta perpassou o levantamento da forma como as análises da pesquisa foram realizadas, buscou-se destacar que a coleta de dados se deu por meio de uma pesquisa do tipo etnográfica; depois, tentouse reconduzir os caminhos percorridos pelos dados levantados e pelos pressupostos teórico-metodológicos que subsidiaram as suas discussões. Com o devido cuidado, procurou-se "afinar" a forma de coleta com a de análise dos dados para, ao final, conduzir as problematizações e discussões de maneira a apontar uma condução que ajudasse no cumprimento dos objetivos da pesquisa.

Portanto, na linha de pensamento que foi adotada para a escrita do relatório do estudo originário, considerou-se necessário, vez por outra, buscar, junto ao repertório teórico-filosófico adotado para a pesquisa, as referências necessárias para a compreensão daquilo que foi chamado de "diapasão entre a coleta e a análise de dados". Isso significa dizer que, mesmo antes das discussões acerca do pensamento de Wittgenstein, utilizado para as problematizações da pesquisa, alguns aspectos de sua teoria foram discutidos para auxiliar na compreensão dos caminhos adotados, tanto para a coleta como para as análises dos dados. 
A expectativa era de que as questões metodológicas adotadas, o repertório teórico-filosófico, as análises e, por fim, as conclusões descritas no relatório da pesquisa, estivessem alinhados de tal maneira que, por vezes, veja-se em uma a outra e vice-versa.

\title{
3 INTERAÇÕES ENTRE A COLETA E A ANÁLISE DE DADOS
}

De acordo com Mattos (201 1, p. 49), fazer et nografia implica:

\begin{abstract}
1) preocupar-se com uma análise holística ou dialética da cultura: 2) introduzir os atores sociais com uma participação ativa e dinâmica e modificadora das estruturas sociais; 3) preocupar-se em revelar as relações e interações significativas de modo a desenvolver a reflexividade sobre a ação de pesquisar, tanto pelo pesquisador quanto pelo pesquisado.
\end{abstract}

A autora sinaliza ainda, para os cuidados que devemos ter quando desenvolvemos pesquisas com o uso desta abordagem, como, por exemplo, o tempo despendido no campo de investigação, a descrição e a minuciosa análise dos dados, o processo de análise conduzido de maneira ética, dentre outros. Outro fator importante que podemos destacar é a não rigidez dos meios e técnicas que podem ser utilizados no momento da aplicação dessa abordagem de pesquisa.

\begin{abstract}
A etnografia é um processo guiado preponderantemente pelo senso questionador do etnógrafo. Deste modo, a utilização de técnicas e procedimentos etnográficos, não segue padrões rígidos ou prédeterminados, mas, sim, o senso que o etnógrafo desenvolve a partir do trabalho de campo no contexto social da pesquisa. Os instrumentos de coleta e análise utilizados nesta abordagem de pesquisa, muitas vezes, têm que ser formuladas ou recriadas para atender à realidade do trabalho de campo. Assim, na maioria das vezes, o processo de pesquisa etnográfica será determinado explícita ou implicitamente pelas questões propostas pelo pesquisador (MATOS, 2011, p. 50).
\end{abstract}

Para uma pesquisa do tipo etnográfica, mas não apenas para ela, o tempo utilizado para o acompanhamento, observações e entrevistas deve ser aquele que se revelar possível e que deve ter por premissa básica não 
"atrapalhar" a rotina dos indivíduos, uma vez que os participantes da pesquisa possuem suas atividades, seus cotidianos.

No entanto, é exatamente o acompanhamento das atividades dos indivíduos, no interior sociocultural em que eles estão inseridos, que o investigador deve sempre buscar observar e registrar o que é feito para, posteriormente, em uma conversa com registro em diário de campo ou mesmo durante as entrevistas, levantar questões acerca das atividades que foram desenvolvidas.

Basicamente, a coleta se dá por meio das seguintes técnicas discutidas resumidamente: observação, registro em diário de campo e em áudio e vídeo e entrevistas semiestruturadas. As atividades cotidianas devem ser observadas e aquelas que não forem possíveis acompanhar, mas, que podem ser relatadas durante as entrevistas, se possivel devem ser registradas em meio digital (gravação em áudio e vídeo) e registro no diário de campo.

Estes registros podem auxiliar para complementar as informações obtidas nas observações, aprofundando, sobremaneira, o entendimento acerca de várias questões que podem surgir. Transcrever os registros pode favorecer melhor entendimento e subsidiar argumentos para posterior análise. A condução das entrevistas deve ocorrer de maneira que possa propiciar aos entrevistados a maior motivação e adesão possíveis para contribuir para a pesquisa.

As entrevistas em pesquisas do tipo etnográficas servem como orientadoras do processo e, assim, para tentar garantir uma coleta consistente de dados, sempre que necessário, o entrevistador (pesquisador) tratará de flexibilizar as questões para tentar não perder o foco. Embora essa flexibilização possa ocorrer por diversas vezes, em alguns momentos, o entrevistador deve deixar a conversa fluir de maneira natural sem, inclusive, intervir de alguma maneira e apenas registrar as respostas.

A flexibilização aqui mencionada, em nenhum momento ou mesmo em nenhum sentido, diz respeito a alterar os rumos das perguntas feitas ou das respostas obtidas durante as entrevistas. Muito menos "facilitar" para que sejam realizadas, mas, apenas, garantir o foco no tema proposto. 


\section{PESQUISAS QUALITATIVAS DO TIPO ETNOGRÁFICAS: a nossa experiência em uma pesquisa em Educação Matemática}

O objetivo principal do estudo que deu forma a este texto era o de compreender o que está manifesto nas práticas matemáticas, dos membros de uma comunidade remanescente de quilombos, da cidade de Alcântara - MA. Para tanto, discutiu-se questões que envolvem a não universalidade destas práticas, como elas têm sobrevivido às problemáticas decorrentes da implantação da Base de Alcântara, a maneira como os sujeitos fazem uso do que ainda lhes restam de tais práticas e como estas lhes auxiliam nas suas atividades cotidianas de trabalho e sobrevivência.

As questões acima apontadas, no que se referem, especificamente, à compreensão das práticas matemáticas, foram problematizadas, a part ir do repertório filosófico de Wittgenstein, especialmente a noção de jogos de linguagem. A utilização desta noção no estudo que realizamos nos auxiliou na compreensão da existência de vários modos de matematizar, ou seja, o compreender como é feito o uso de "práticas matemáticas" em contextos específicos, nos quais o sujeito está inserido, sem que, necessariamente, isso se dê por meio da escolarização formal (CASTRO; CALDEIRA, 2017). Pois, tem relação direta com a maneira com que os indivíduos se relacionam em sociedade e, principalmente, como esta relação se dá enquanto componente cultural da forma como estes mesmos indivíduos se organizam e estabelecem regras próprias de convívio e sobrevivência.

Para Wittgenstein (2014, p. 27, § 23), "a expressão jogo de linguagem deve salientar aqui que falar uma língua é parte de uma atividade ou de uma forma de vida". Wittgenstein articula a noção de jogos de linguagem a partir de vários aspectos relativos à ação social na qual a linguagem está inserida e é exatamente por isso que a utilização do seu pensamento servenos de ferramenta para analisar as práticas matemáticas, uma vez que, de acordo com Vilela (2013, p. 175) tais práticas são compreendidas "[...] como um conjunto variado de jogos de linguagem ou diferentes usos de conceitos matemáticos em práticas específicas". 


\section{ISSN 2237-9460}

Quando nos propusemos a realizar uma pesquisa que faça a análise de tais jogos de linguagem, utilizamos para a coleta dos dados a pesquisa qualitativa do tipo etnográfica. Ela nos deu o suporte que consideramos necessário para a busca das compreensões que alcançamos. Assim, entender aspectos desse tipo de pesquisa e de como podemos fazer uso dela nas pesquisas que realizamos, certamente abrirá outros caminhos para as pesquisas em Educação Matemática.

Desta forma, partimos primeiro, da busca por entender alguns de seus elementos. De acordo com Bogdan e Biklen (1994), aqueles que se ocupam em realizar investigações qualitativas têm com o significado, bem como outras características desse tipo de pesquisa, a preocupação com os fundamentos teóricos da abordagem. Em uma investigação qualitativa, o ambiente natural é o principal instrumento do investigador. É por ele e para ele que $o$ investigador, imbuído do desejo de conhecer para melhor compreender, ao longo de toda investigação constitui as descrições necessárias que servirão de base para suas análises.

Partindo desta compreensão, a investigação que originou este texto teve por base preceitos supracitados. No entanto, para que não sejamos vistos como contraditórios em algum momento, precisamos esclarecer alguns pontos: (1) o estudo realizado (que fez uso da pesquisa do tipo etnográfica) não teve a pretensão de se fechar nele mesmo, e muito menos no pesquisador ou nos problemas com que porventura se deparasse; (2) não teve a característica de apontar soluções, visto que, nenhuma pesquisa que possua esta forma constitutiva e de desenvolvimento tem esta intenção.

Outro ponto que precisa ser reafirmado é que, em seu desenvolvimento, não se pretendeu ir ao encontro do fenômeno-em-si, não foi intenção criar um caminho concreto, rígido, imóvel que ao fim e ao cabo, colocasse-nos "face a face" com o objeto. Constituiu-se em um movimento de idas e voltas, de encontros e desencontros, de trilhas tortuosas pelas quais o tempo escorregava entre os dedos e nada, absolutamente nada, chegava aos olhos, aos sentidos, à caneta. 
Foi com base nisso, que se acredita que a pesquisa do tipo etnográfica se apresentou como possibilidade de uso nas análises e problematizações das práticas matemáticas da comunidade, pois, desta forma, pretendeu-se compreender aspectos inerentes aos usos que seus membros fazem de tais práticas, buscando apreender os sentidos e significados a elas atribuídas, sem, no entanto, apontar ou sugerir problemas e suas respectivas soluções.

Ainda no que diz respeito às questões metodológicas, por uma necessidade do próprio campo no qual a pesquisa estava inserida e, por uma necessidade do próprio investigador, na pesquisa do tipo et nográfica, o "caminho" a ser adotado deve ter por base a necessidade de estar presente. Neste tipo de pesquisa, a permanência e a atitude do pesquisador no campo da pesquisa buscam compreender a "lógica de funcionamento" do grupo social e as estratégias utilizadas por seus membros para o desenvolvimento de suas atividades. Desta maneira, o estar presente se faz como atitude de observação, não a observação por observação pura e simples, mas, sim, aquela que o pesquisador tenha a sensibilidade necessária para saber quando e se é possivel "intervir3" e como isso se dará.

Durante as análises do estudo que originou este texto, de pronto, percebemos que a maior parte das atividades se dava através do plantio de alguma cultura, principalmente, a mandioca para a fabricação de farinha. Além da pesca, apesar de agora a comunidade encontrar-se a uma longa distância do mar, e das dificuldades que estas pessoas têm para locomoverse até lá. As descrições realizadas destacaram as diversas maneiras com que isso ocorre e buscaram enfatizar o uso das práticas matemáticas como elemento essencial para o desenvolvimento destas práticas sociais, mesmo que os indivíduos não atentem de maneira clara para isso.

\footnotetext{
3 Compreenda-se o termo intervir não como uma ação na realidade observada, mas, sim, como uma possibilidade de alteração da forma como o pesquisador faz o trabalho de campo, ou seja, como este pode, a depender da maneira como a própria realidade se apresenta, alterar os caminhos das técnicas que utiliza sem modificar o sentido daquilo que busca compreender.
} 
No que tange à aplicação da pesquisa do tipo etnográfica em relação a este fato, foi possivel perceber, por meio das técnicas empregadas, que a diversidade das práticas matemáticas, como elementos constituintes de suas práticas sociais mais amplas, é fundamental para a vida cotidiana destes povos. A pesquisa qualitativa do tipo etnográfica utilizada favoreceu esta compreensão, à medida que possibilitou adentrar e permanecer por relativo tempo na comunidade.

Desta forma, de acordo com Groulx (2012, p. 95), uma investigação deste tipo se constitui em espaço de observação de "(...) práticas relativamente diversificadas e múltiplas" e são essas diversificadas formas de saber e fazer que permitem a sobrevivência destes povos por tantos anos. Este tipo de pesquisa tem ainda a característica de considerar as pessoas, seus ambientes e relações socioculturais, experiências de vida, etc. - e que, por isso, não pode ser uniformizada, não pode seguir um padrão e, sim, favorecer uma postura plural na ação do investigador -, por este motivo e pelas características do estudo originário, adotou-se essa perspectiva metodológica.

Assim, a pesquisa do tipo etnográfica aplicada ao estudo que deu forma a este texto é vista como um caminhar para desconstruir, repensar o pensamento, romper com critérios antes estabelecidos. Neste sentido, não tem a pretensão de alcançar o início, nem o meio, muito menos o fim. Nem sequer de reconstruir nada perdido, outrora esquecido, ou refazer a origem analítica dos acontecimentos, apenas constituir-se como possibilidade de entendimento, de entender-se e buscar ser entendida.

\section{CONCLUSÃO}

Como dito linhas acima, o estudo que deu origem a este texto foi desenvolvido por meio de uma pesquisa do tipo etnográfica e tinha por objetivo analisar as práticas matemáticas, compreendidas como jogos de linguagens matemáticos, e a sua não universalização, problematizando-as, a partir do repertório teórico-filosófico de Wittgenstein. O intuito era o de decodificá-las e ressignificá-las, na tentativa de registrá-las, de maneira que 
tal registro considerasse seus elementos de pertencimento a uma comunidade quilombola tradicional, a territorialidade e a ancestralidade 4 , ou seja, seus componentes culturais diversos e, assim, possibilitar que sejam constantemente revisitados, contribuindo para que não se percam.

Desta forma, buscou-se descrever aspectos das práticas sociais estabelecidas no seio da comunidade que, de alguma forma, têm relação direta com as práticas matemáticas desenvolvidas e seus respectivos usos. $\bigcirc$ interesse era buscar compreender como tais práticas auxiliam na realização das atividades cotidianas dos sujeitos pertencentes à comunidade e isso encaminhou para o entendimento de que os deslocamentos, reassentamentos e realocações compulsórias ocorridas, influenciaram em grande medida na mudança na forma com as práticas sociais, e dentre elas as práticas matemáticas, são desenvolvidas e utilizadas atualmente.

A pesquisa do tipo etnográfica foi fundamental para as compreensões obtidas e para as problematizações realizadas no estudo originário. Foi possível estabelecer relações entre os aspectos metodológicos de coleta e análises dos dados, quanto os de alinhamento destes com os argumentos teórico-filosóficos que serviram de auxílio para as discussões que seus objetivos propunham. Essa é uma das primeiras atitudes do pesquisador quando fizer uso dessa modalidade de pesquisa.

Outro aspecto que deve ser discutido, de maneira a evitar, ou mesmo minimizar, equívocos quando deste "alinhamento", diz respeito ao fato de que o pesquisador tem que se fazer reconhecer, reconhecer os sujeitos da pesquisa e, mais ainda, fazer o possível para que este reconhecimento ocorra no tempo necessário para que seja posto em prática um diapasão entre a coleta e as análises dos dados apresentados.

Isso só será possível se, também considerarmos novamente que o aporte teórico-filosófico que a pesquisa apresenta estiver relacionado

4 De acordo com o Decreto $n^{\circ} 4887 / 2003$, art. $2^{\circ}$, consideram-se remanescentes das comunidades dos quilombos, para os fins deste Decreto, os grupos étnico-raciais, segundo critérios de autoatribuição, com trajetória histórica própria, dotados de relações territoriais específicas, com presunção de ancestralidade negra relacionada com a resistência à opressão histórica sofrida (BRASIL, 2003). 
diretamente com aquilo que os objetivos pretendem alcançar, ou seja, se alinhavarmos objetivos, aporte teórico-filosófico e metodologia, e sobre este último aspecto, como se deve proceder para evitar contrassensos, ou pelo menos tentar minimizá-los, para que os resultados da pesquisa sejam coerentes e, por fim, o pesquisador e os sujeitos da pesquisa se façam reconhecer nela. A partir disso, a preocupação com as análises e a metodologia das pesquisas em Educação Matemática, deve ser aquela, na qual se considera de acordo com o repertório teórico-filosófico adotado e, desta forma, se durante sua realização os elementos que possibilitem as problematizações, levantamentos e posterior discussão estão em constante alinhamento com a proposta da pesquisa.

Por vezes, a dificuldade encontrada neste aspecto diz respeito a como realizar o enlace entre aspectos de uma pesquisa qualitativa do tipo etnográfica e seus aspectos de análises, e mais, como fazer isso sem incorrer em erros. Desta feita, para constituir o que aqui, se ousa denominar de "uma experiência teórico-metodológica para análises de dados qualitativos, oriundos de uma pesquisa do tipo etnográfica", argumenta-se acerca desta experiência de conduzir as análises do estudo de maneira a compreender os elementos socioculturais mutáveis, seja no sentido de sua elaboração prática, seja naquilo que os tornam efetivamente parte de sua constituição histórica.

Dito isto, as pesquisas do tipo etnográficas devem buscar refletir a partir da ideia das práticas sociais mais amplas, ao se constituírem como parte dos elementos socioculturais nos quais as pesquisas em Educação Matemática estão inseridas, visando, sobretudo, consolidá-la como promissor campo de pesquisa.

Tendo por base a pesquisa que originou este texto, é possível dizer que, com a utilização da pesquisa do tipo etnográfica, buscou-se nos dados levantados, a reflexão sobre o passado, em um tempo histórico, relativamente curto - aquele em que as suas vidas foram alteradas, a partir da implantação da Base de Alcântara -, para tentar compreender seus efeitos, por meio das significações que das falas emergem. 
Porquanto, convém ainda ressaltar, que o diapasão proposto entre aquilo que foi possível captar por meio da pesquisa do tipo etnográfica e as suas análises, consubstanciadas, em certo modo, nas discussões e problematizações surgidas entre elas, buscou ser minimamente coerente com o seu aspecto teórico-filosófico. A discussão proposta acerca das práticas matemáticas constituídas no seio de práticas culturais específicas como, por exemplo, a fabricação de farinha de mandioca, visa compreender em que medidas tais práticas auxiliam e proporcionam meios de subsistência para os indivíduos desta comunidade.

O contexto, as situações vividas, o espaço-tempo da pesquisa e as mais variadas maneiras de abordá-los já são elementos constituintes das análises e compõem, assim, parte significativa do trabalho científico que é proposto. Desta maneira, procurou-se na microanálise etnográfica, instrumento da etnografia que pode ser perfeitamente utilizado na prática das pesquisas, dar ênfase às análises, aos significados atribuídos pelos sujeitos da pesquisa, às suas práticas matemáticas constituídas como jogos de linguagem matemáticos.

O que se deve buscar no objeto ou fenômeno de estudo é partir de um contexto, para olhar a sua unidade e poder destacar a sua particularidade, sem que isso se caracterize como algo fixo ou de caráter imutável. $\mathrm{O}$ que se pretende ao utilizar desta proposta de abordagem de pesquisa é particularizar uma atividade sociocultural específica, que possibilite discutir nas análises das pesquisas em Educação Matemática, e ilustrar a pequena parcela dos modos de fazer e ser do grupo em estudo, possibilitando ao pesquisador o encontro do significado que o grupo atribui àquela atividade, na qual os objetivos da pesquisa buscam compreender.

No estudo desenvolvido, que fez uso da pesquisa do tipo etnográfica, procurou-se identificar as formas, relações e interações acerca dos jogos de linguagem matemáticos, sob a perspectiva do grupo, como as desenvolvem e como as manifestam para, desta forma, nas problematizações e análises realizadas, se proceder e discutir, a partir das descrições propostas da seguinte maneira: 
1. proceder com um recorte de tempo e delimitar uma, dentre as atividades que nos foram apresentadas e que consideramos relevante para a pesquisa;

2. considerar que tanto o tempo, quanto a atividade, devem nos permitir descrever as interações sociais nas quais, no caso específico, as práticas matemáticas estão inseridas e o tempo de realização da pesquisa;

3. destacar nas descrições referidas acima, as interações entre os indivíduos e entre estes e as práticas descritas, ou seja, aquilo que efetivamente poderá ser descrito de maneira a contribuir para que a particularização seja realizada sem que se corra $\circ$ risco de quebrar os aspectos teórico-filosóficos que a pesquisa abraçou e sem caracterizar uma suposta "universalização".

Por meio das descrições referenciadas, deve-se tentar elencar elementos que favoreçam as compreensões e cumpram os objetivos que a pesquisa traçou. Portanto, é essencial que se torne evidente, como o processo de observação e coleta de dados ocorreu para, em seguida, marcar o recorte de tempo e a atividade em que a pesquisa se desenvolveu, como possibilidade de compreender seus aspectos constitutivos e de se proceder com as captações das interações mencionadas. É importante destacar que, para o desenvolvimento das análises da pesquisa desenvolvida e que deu origem a este texto, alguns estudos realizados recentemente no campo das discussões acerca da forma de como tem se dado o conhecimento, tradicional ou não, formal ou não, também foram utilizados.

Neste sentido, além das características descritas acerca do aporte metodológico e, considerando ainda, o diapasão discutido páginas anteriores, as discussões acerca das noções filosóficas de Wittgenstein, que fizeram parte do escopo da pesquisa - e que tiveram por objetivo subsidiar as discussões e análises em torno das várias questões apontadas pelos dados levantados por meio de uma pesquisa do tipo etnográfica - foram fundamentais. 
Outro aspecto que auxiliou na compreensão proposta diz respeito às descrições das práticas matemáticas. Descrevê-las de maneira crítica, não apenas a descrição pela descrição, mas, sim, referenciada e alicerçada nos pressupostos teórico-filosóficos adotados, possibilitou compreender como ocorrem seus variados usos nas atividades cotidianas desta comunidade, bem como a maneira com que tais práticas se constituem como verdades nos usos para os membros da comunidade.

Buscou-se descrever as práticas sociais estabelecidas no seio da comunidade para, a partir delas, de alguma forma, descrever aquelas que têm relação direta com as suas práticas matemáticas. O exposto acima foi realizado com o objetivo de caracterizar as práticas matemáticas como elementos culturais e constitutivos de suas ancestralidades. Observou-se, no entanto, que para isso não foi necessária a busca pela origem destas práticas, mas, como elas estão diretamente relacionadas com o local e o cultural num tempo determinado.

Os objetivos propostos na pesquisa, aliados à pesquisa do tipo etnográfica, e principalmente por meio dela, favoreceram a compreensão acerca da forma como as práticas matemáticas são parte dos elementos socioculturais da comunidade estudada. Desta forma, foi possível salientar as particularidades destas práticas sociais cotidianas que têm por base aspectos relativos às atividades de trabalho. A compreensão de que as práticas matemáticas, sendo parte dos elementos que compõem suas relações sociais e suas subjetividades, permitem a garantia da manutenção e ampliação dos seus saberes e fazeres. Esta, sem dúvidas, foi uma das mais importantes compreensões a que a pesquisa desenvolvida chegou.

Com isso, a pesquisa qualitativa, na perspectiva da pesquisa do tipo etnográfica, também auxiliou nessa compreensão à medida que permitiu adentrar no "universo" particular da comunidade que foi estudada e, de lá, buscar entender os sentidos e significados que a comunidade atribui a estes saberes e fazeres. Isso é dito, primeiramente, porque nos permitiu entender que estas práticas matemáticas são constituintes de suas práticas sociais e, depois, por carregarem consigo, parte de suas tradições, saberes e fazeres; 
e, finalmente, por permitem a esses indivíduos suprir parte de suas necessidades com suas subsistências.

As práticas matemáticas possuem significados atribuídos pelas formas de vida e, assim, conforme os jogos de linguagem matemáticos são postos em prática, desenvolvem-se práticas matemáticas específicas que possibilitem a existência e a garantia de meios de sobrevivência e subsistência. Verificamos que a pesquisa do tipo etnográfica, alvo deste texto, em contextos que envolvam as pesquisas em Educação Matemática, podem favorecer a busca por compreender realidades sociais, sobretudo com a imersão do pesquisador, no meio no qual a pesquisa se realiza e, por conseguinte, compreender aspectos das práticas matemáticas que envolvem e fazem parte destas relações sociais, principalmente, quando são postos em evidência, à medida que os indivíduos realizam suas tarefas cotidianas.

\section{REFERÊNCIAS}

ALMEIDA, A.W. B. de. Os quilombolase a base de lançamento de foguetes de Alcântara: laudo antropológico. Vol. 1 - Brasília: MMA, 2006.

BOGDAN, R. C; BIKLEN, S. K. Investigação Qualitativa em Educação: uma introdução à teoria e aos métodos. Coleção Ciências da Educação. Porto: Editora Porto, 1994.

BRASIL. Decreto $N^{\circ}$ 4.887, de 20 de novembro de 2003. Regulamenta o procedimento para identificação, reconhecimento, delimitação, demarcação e titulação das terras ocupadas por remanescentes das comunidades dos quilombos de que trata o art. 68 do A to das Disposições Constitucionais Transit órias. Diário Oficial, Brasília, DF, 20 de nov. 2003, Seção 2, p. 3.

CASTRO, R. S. de.; CALDEIRA, A.D. Entrelaçamentos e Possibilidades dos Jogos de Linguagem Matemáticos: seus usos na comunidade remanescente de Quilombos da Agrovila de Espera, Alcântara-MA. Revist a Exitus, Santarém/PA, v. 7, n. 2, p. 32-54, Maio/Ago. 2017.

CHIZZOTTI, A. Pesquisa Qualitativa em Ciências Humanase Sociais. 5. ed. Petrópolis: Vozes, 2013. 
FREITAS, E. C. de; PRODANOV, C. C.. Metodologia do trabalho científico [recurso eletrônico]: métodos e técnicas da pesquisa e do trabalho acadêmico. 2. ed. Novo Hamburgo: FEEVALE, 2013.

GROULX, L. H. Contribuições da Pesquisa Qualitativa à Pesquisa Social. In: POUPART, Jean et al. Pesquisa Qualitativa: enfoques epistemológicos e metodológicos. 3. ed. Petrópolis: Vozes, 2012.

LIMA, C. M. G. de; DUPAS, G.; OLIVEIRA, I. de; KAKEHASHI, S. Pesquisa etnográfica: iniciando sua compreensão. Rev. Latino-americana de Enfermagem, Ribeirão Preto, v. 4, n. 1, p. 21-30, 1996.

MA GNANI, José Guilherme Cantor. Etnografia como Prática e Experiência. Horizontes Antropológicos, Porto Alegre, v. 15, n. 32, p. 129-156, Jul./Dez. 2009.

MATTOS, C. L. G.; CASTRO, P. A.; orgs. Ełnografia e educação: conceitos e usos [online]. Campina Grande: EDUEPB, 2011 (a).

MATTOS, C. L. G. de. A abordagem etnográfica na investigação científica. In: MATTOS, C. L. G.; CASTRO, P. A. (Org.). Ełnografia e educação: conceitos e usos. Campina Grande: EDUEPB, 2011. p. 49-83.

SOUSA, L. B. de, BARROSO, M. G. T. Pesquisa etnográfica: evolução e aplicação. Esc. Anna Nery Rev. Enfermagem, v. 12, n. 1, p. 150-155, 2008.

VILELA, D. S. Usos e Jogos de Linguagem na Matemática: diálogo entre Filosofia e Educação Matemática. São Paulo: Editora da Física, 2013.

WITTGENSTEIN, L. Investigações Filosóficas. 9.ed. Editora Vozes: Petrópolis - RJ, 2014.

Recebido em: 28 de março de 2018. Aprovado em: 07 de janeiro de 2019. 